\title{
Researchers contest reports of tree death
}

Munich. Controversy has broken out in Germany following the publication of a report from an independent forestry research institute, which, its authors argue, contradicts dire warnings that forests in Europe - particularly Germany and the Czech Republic - are sickening and dying.

The report is based on 22 studies in 12 countries, which show that tree growth in Europe has actually increased over the past few decades. It has been published by the European Forest Institute (EFI), an independent research institute based in Finland, and released during EFI's annual meeting in Freiburg, Germany.

But newspaper reports highlighting statements made at the press conference have upset many other European forestry scientists and conservationists. They argue that the interpretation of the studies is invalid, as they measured only the height and diameter of trees, and did not consider other parameters relevant to the health of trees such as soil conditions and loss of leaves or needles.

The EFI receives half its funds from the government of Finland, for which forestry is a major industry, and half from 67 scientific institutes in other European countries. According to its new report, there is no clear growth trend of trees in the most northern regions of Europe. But a positive trend can be clearly seen in most regions of central Europe and in some in southern Europe, where human population is denser and pollution greater.

The report suggests that possible causes

\section{IMAGE \\ UNAVAILABLE FOR COPYRIGHT REASONS}

Pining away? The disputed study suggests increasing tree growth in central Europe.

of faster growth could be increased levels of soil nitrogen and atmospheric carbon dioxide from traffic exhaust, local climate changes, or the fact that many of the forests observed are relatively young, having been replanted following extensive tree-felling after the Second World War.

Critics of the report accept the basic data. But they argue that the rate of tree growth gives no indication of health of trees. "The trees are simply growing themselves to death," says Hubert Weinzierl, chairman of the German conservation group, BUND, who interprets the data as suggesting that $\approx$ the increased growth is a reaction to their intrinsic damage.

This position is supported by the Research Centre for Forest Ecosystems at the University of Göttingen. Michael Bredemeier, its scientific secretary, argues that the increased growth of trees is associated with "chronic shock and weakness". But Heinrich Spiecker, who co-authored the EFI report, in turn questions the validity of data that have stimulated fears that German forests are dying.

The forestry department of the German federal ministry of agriculture, for example, has been monitoring the loss of leaves and needles from trees in 5,000 sites in Germany since 1983. Its latest figures indicate that more than 60 per cent of the trees under observation were damaged, as assessed by such loss, and a quarter badly damaged.

But Spiecker says that there is no proof that leaf and needle loss indicates that trees are dying. He concedes that the data in the EFI report are open to interpretation. Nevertheless, he says, he expects to see "no catastrophic loss of forest in the near future".

The European Commission disagrees. According to a recently published survey of forest conditions in the European Union, which has been running since 1987 , one in five of all trees at specified sites throughout the union show clear signs of leaf or needle damage, and the extent of damage is greatest in central Europe. Thus damage appears to correlate with increased growth.

Alison Abbott

\section{UN biodiversity advisers warned: stick to science}

London. The chairman of a panel of scientific advisers to the United Nations (UN) biodiversity convention, signed at the Earth Summit in Rio de Janeiro in 1992 to provide a framework for protecting global biodiversity, has urged his members to restrict their advice to scientific issues, amid signs that some are using the body as a political forum.

Peter Schei, chairman of the convention's Subsidiary Body on Scientific, Technical and Technological Advice (SBSTTA), repeatedly urged members during a meeting in Montreal, Canada, earlier this month to avoid digressing into discussions on the politics of biodiversity. The subsidiary body was neither a "mini-conference of the parties" nor a "[policy] drafting group", said Schei, who is a biodiversity adviser to Norway's environment minister, Torbjoern Berntsen. "We are a scientific advisory body." SBSTTA, he added, needs to improve its cooperation with the scientific community.

Among other topics, the meeting considered the monitoring and assessment of biodiversity, practical approaches to taxonomy, and the economic valuation of biodiversity.
But sharp disagreement emerged during discussions on agricultural biodiversity, involving the need to balance the preservation of forests and other natural ecosystems against pressures to clear land for farming. There was also disagreement on the issue of indigenous knowledge and biodiversity conservation.

Nevertheless, Schei says the meeting was less discordant than he had envisaged, while acknowledging that government-appointed scientists often find it difficult to remain impartial in an area with a strong political dimension. For example, he says, some scientists see the question of indigenous knowledge as inevitably involving the protection of the rights of indigenous people. "That is taking the job of SBSTTA too far."

The biodiversity convention came into force in December 1993 and now counts more than 150 countries as 'parties' - those that have signed the convention and ratified it in their national parliaments. A spokesman for the International Institute for Sustainable Development, an environmentalist group based in Canada that closely follows all UN environmental agreements, said that SBSTTA has an additional handicap: the fact that some of its members are not scientists at all, which is putting the body's scientific authority under strain.

According to some participants, delegates often arrive with national priorities in mind and are the same people who attend the annual meeting of countries that have signed the biodiversity convention, known as the Conference of the Parties. But Ann Brocklehurst, a spokeswoman for the convention, says such countries "are in a minority".

Schei agrees that scientists advising the biodiversity convention face similar difficulties to those advising the climate convention: having to advise governments on issues whose scientific underpinnings may be relatively weak. But he says he would not want to discourage the practice of governments sending the same group of delegates to both the scientific and political segments of the convention. "People who go to both have a better understanding [than raw scientists] of the transfer of scientific know-how into sound policy-making."

Ehsan Masood 